\title{
Knowledge Representation of Social and Coalition Factors in Coalition Formation Using An Ontology Framework
}

\author{
Azleena Mohd Kassim, Yu-N Cheah, and Bukhary Ikhwan Ismail
}

\begin{abstract}
Cooperative work from the computational aspects can be addressed in the area of coalition formation where it is driven to accomplish optimal groups to perform certain given tasks. For a human-centric coalition formation, recent works usually focus on individual capability related to the task, but the social aspects are often neglected. Besides, coalition formation is often applied or used as a one-off process whereby the formed coalitions and its knowledge are not stored or reused. Thus, the objective of this paper is to present a new framework for coalition formation known as the Social- and Knowledge-based Coalition Formation (SKCF). The sub-objectives are: 1) to define coalition and social factors for a coalition formation model, 2) to build knowledge representation scheme to store knowledge from coalitions that are successfully formed. To achieve the objective, the social and coalition factors are compiled from existing related works to suit the objective of forming groups of people in a cooperative setting. The ontology is introduced as a knowledge repository where the representation schema of the ontology is developed to manage and reuse the social and coalition factors.
\end{abstract}

Index Terms - Coalition factors, knowledge management, ontology representation, social factors.

\section{INTRODUCTION}

One of the earliest theory of coalition formation was presented by Neumann and Morgenstern [1] where they used game theory to discover the economic behavior and benefits of forming coalitions. Since then, coalition formation approaches have been explored in numerous different angles and applied in different domains. In computing field, coalition formation approach is motivated to achieve optimal groups, set to perform a certain set of tasks. The approach of coalition formation is substantial in scenarios where a goal is better accomplished in a group than by an individual. Coalition formation can be treated as a dynamic process in computing field; where the payoffs are created when the coalitions are formed, split up and regrouped [2]. Ray and Vohra [2] also highlighted the equilibrium distribution of the coalition as one of the important aspects of coalition formation. Therefore, a computing system that performs coalition formation should be capable of intelligently form a group, disintegrate the group or regroup when required.

Coalition formation can be adapted to assign resources in equilibrium, as such where the resources are used to solve different computing issues, for example virtual machine problems, network configuration and multi-agent systems.

Manuscript received February 12, 2018; revised May 10, 2018.

The authors are with Universiti Sains Malaysia, Malaysia (e-mail: azleena.mk@usm.my).
The performance of agents in coalition formation can be enhanced when the efforts and resources are combined efficiently in order to perform the given tasks [3]. Elkind $e t$ al. [3] carried out an extensive review on coalition formation systems and determined that there are two types of coalition formation: 1) Cooperative agents who share common goals to achieve an optimal distribution, and 2) Selfish agents who only care about their payoffs. Selfish agents approach is important as the focus is given on how the gains can be distributed optimally and in equilibrium since payoff motivates the agents to take part in a coalition.

In human-centric coalition formation, most existing methods emphasize on the computational and structural aspects [4]. Many coalition formation multi-agent systems use the cooperative game theory which seems to be too abstract to be useful in modeling real-world cooperative scenarios [5].

Some coalition formation approaches focus on individualistic attributes but the cohesiveness of a coalition as a whole is often disregarded [2], [4]. In human-centric coalition formation, individualistic attributes are useful in recognizing whether a specific person is suitable to perform a certain task. Nonetheless, the influence of relationship among individuals to attain an optimal coalition needs to be explored. Sless et al. [5] utilized cohesiveness of a coalition by concentrating on the relationship of people where they are represented as a weighted graph of a social network. But other factor like the skills to carry on a specific task is not included. The relationship is based on the people's association to each other without considering the quality of the relationship therefore the overall cohesiveness can be questioned.

The knowledge created when a coalition is formed is often disregarded as coalition formation is treated as a onetime process. Knowledge from coalitions that are formed and the evaluation of a coalition can be stored and reused for future coalitions. Accordingly, it is important to define a framework for knowledge management, storage and reuse to ensure the knowledge can be easily assessed and reused.

The main objective of this paper is to present a new framework known as Social- and Knowledge-based Coalition Formation (SKCF) as a coalition formation model to form groups of people to complete given tasks. The subobjectives to support the main objective are: 1 ) to define the social and coalition factors for the coalition formation model, 2) to develop a knowledge representation schema using ontology representation.

As a result, a new coalition formation framework is developed with the help of ontology. The coalition formation model incorporates a knowledge base in the 
coalition formation so that the knowledge created within the process can be captured, stored and reused. The SKCF model can later be adapted to several other functions in an organization where building a collaborative team or group is concerned.

\section{RELATED WORKS}

Ray and Vohra [2] presented a widespread analysis of coalition formation as a dynamic process by scrutinizing the theory of dynamic coalition formation. They presented the details of how equilibrium process is defined in coalition formation. Ray and Vohra [2] presented the coalition features that are in a dynamic state and produced methods of representing the dynamic coalition formation. Ray and Vohra [2] mentioned that the presented dynamic coalition formation was just a proposed approach and not a general theory; therefore it is flexible to be adopted or further explored. However, other computational aspects such as the storage, reusability or sustainability of coalition were not focused by Ray and Vohra [2], thus can be addressed in order to develop a more advantageous coalition formation system.

Coalition formation in a multi-agent system (MAS) comprises of numerous interacting intelligent agents in a computational environment. Elkind et al. [3] underlined two approaches of the coalition formation for MAS which are the: 1) Selfish agents, where agents are only concerned on their own payoffs. For example, the agents emphasize on the distribution of gains from a coalition as to participate in the coalitional solution, the agents expects some incentive or benefit. 2) Cooperative agents, where the agents share a common goal and finding optimal way to distribute agents into groups. Coalition formation involving human such as work by Sless et al. [5], Boella et al. [6] and Pechoucek et al. [7] focused on the cooperative agent approach without concentrating on the payoff benefits of the coalition. This gap can be tackled where in the computational coalition formation; the combined approach can maximize the strength of both approaches. The factors that can maximize the payoff of a coalition formation system need to be identified, and subsequently the method on storing and reusing these factors need to be determined.

Cho et al. [8] presented the factor trust as a payoff in a human-centric coalition formation, but they highlighted the need to define the payoff in a way to satisfy multiple objectives. Thus, besides the factor trust, other human related factors can be further explored to be considered as other factors in order to be treated as a multi-objective factor in a coalition formation.

Sless et al. [5] employed the social network environment for a coalition formation model, focusing on cooperative agent approach to develop the cooperative structure for the coalition. Sless et al. [5] developed the social network to use the relationships strength between agents by using weighted graph for the relationships in the edges in vertices of social networks. It shows how a human related factor like relationship is used to define the formation of coalitions. This factor can be combined with other factor such as trust, as presented by Cho et al [8] and other social factors, together with existing coalition factors in order to maximize benefits for the coalition formation model.

Another important aspect presented in this paper is for the coalition formation to be a knowledge-based system. Thus, the ideal technology in this case will be one that can support the management, storage and reuse of knowledge.

The ontology model is seemed to be appropriate as it accommodates knowledge management. Ontology model is beneficial to many applications such as intelligent information integration, semantic web and knowledgebased systems, as it is seen to be expressive and computable in the same time [9].

Fensel [10] highlighted the difference between ontology and database schema and ontology was shown to have some advantages over database. For example, ontology is syntactically and semantically richer compared to database. Moreover, ontology describes information in semistructured natural language texts whereas database represents in tabular form. Another appealing feature of ontology is that it is made to be shared to allow information sharing and exchange. Resource Description Framework (RDF) is a standard in ontology that describes data semantically and can be understood by machine. Chebba et al. [9] reported that the Ontology Web Language (OWL) is one of description languages used for expressing ontologies, which is based on RDF schema [11]. OWL is a W3C representation and commonly used in the semantic web to represent knowledge. Fensel [10] presented some available representation methods that can be applied to many knowledge-based systems. But the structure of ontology may vary for different domains in the knowledge-based systems. For example, for a knowledge-based coalition formation system, the ontology structure developed need to be able to cater to instances and factors available in coalition formation model based on the requirements underlined, thus a new framework to represent the coalition formation needs to be developed.

Belsis and Gritzalis [12] made use of RDF ontology framework for coalition formation problem i.e. the security management and the joint administration of resources. The RDF ontology framework was used for policy recording to provide better organizational structure by developing an architecture that has the essential principles of collaborative interoperation of domains. The representation structure in the coalition formation can be adapted to different types of domain environment; alas a new framework of ontology needs to be developed if the coalition formation specifications and structure is intended to be different.

Golbeck and Hendler [13] used the ontology to create "trust network" on the semantic web where it stores the trust representation. The semantic web of trust entails the user to define their beliefs (trust) about others in the same network. Golbeck and Hendler [13] used the Friend-of-aFriend (FOAF) scheme of ontology to generate the interlink statements who he or she knows, and used RDF vocabulary where the user can define the information about themselves and relationship to others. The trust level corresponds from 1-9 with 1 being "distrust absolutely" and 9 - "trust absolutely". Using the social network environment, Albiston et al. [14] extended the work by Golbeck and Hendler [13] for a web-based car-sharing application. Albiston et al. [14] presented a framework with properties 
of trust and distrust in interpersonal relations, and the key concepts. Albiston et al. [14] used the external information sources like public social networks and existing standard vocabularies to enrich the knowledge base. The representation of trust by Albiston et al. [14] and Golbeck and Hendler [13] can be adapted to coalition formation that has trust as one of the factors in a coalition. Nonetheless, the structure on how this representation can be incorporated to the coalition formation structure needs to be further explored.

The use of ontology has varied in many different domains. The researchers commonly propose a new ontology framework to fit the requirements of the problem in the respective domains. Li et al. [15] developed ontology for crop cultivation standard (CCS) by combining domain ontology that contains static information during growing with task ontology, built based on plant process. The CCS ontology was designed to implement planting standard management system because, although there are other ontology being built in agricultural area, they are not unified. Li et al. [15] used ontology tools such as Protégé and OWL to set up the ontology. The outcome of the research was claimed to be an efficient knowledge management for CCS and improved quality of agricultural information services.

Lamharhar et al. [16] used the OWL standard by utilizing ontology and Semantic Web Services (SWS) to build an eGovernment knowledge base and in order to minimize the cost and time of development, sets of existing ontologies, standards and metadata were reused. Lamharhar et al. [16] used conceptual graphs theory to develop the semantic based on conceptual structures model. They claimed the approach presented to be efficient by presenting a prototype of Moroccan e-Government by developing a set of specific ontologies that match the Moroccan e-Government requirements. This shows that an ontology framework needs to be redesigned based on specific requirements based on certain domain and specific entity.

Other works such as by Sankat et al. [17] proposed a method to generate domain ontology for educational domain using protégé tool by taking the semantic into context when information from different modules are displayed. Sankat et al. [17] presented on how structure is transformed into formal domain ontology and also specified steps to transform taxonomy to domain concept. They reported that more complex concepts can be generated by exploiting the existing ontology to realize the educational objective.

\section{IDENTIFICATION OF FACTORS FOR SOCIAL AND KNOWLEDGE-BASED COALITION FORMATION SYSTEM}

In order to develop the SKCF model, the combination of cooperative and selfish agent approach is proposed. This section focuses on the identification of the coalition and social factors for the SKCF. Then, the ontology is used to handle the knowledge for the coalition formation.

\section{A. Identification of Coalition Factors}

The factors considered are motivated by the question "what makes a coalition?" Based on related works in coalition formation, the factors are adopted as presented in Table I. These works underlined some factors based on their specific requirements set to solve a coalition formation problem in their domains. The cooperative agent or selfish agent approach, although was not explicitly stated in their works, are identified and presented in this table. The works in human-centric domain listed used the cooperative agent approach without taking into account the payoff or benefit of each agent individually.

TABLE I: COMPILATION OF COALITION FACTORS FROM SOME COALITION

\begin{tabular}{|c|c|c|c|c|}
\hline \multicolumn{5}{|c|}{ FORMATION WORKS } \\
\hline Reference & Domain & $\mathbf{C A}$ & SA & Factors \\
\hline $\begin{array}{l}\text { Liu et al. } \\
{[18]}\end{array}$ & $\begin{array}{l}\text { Coalition structure } \\
\text { generation problem in } \\
\text { coalitional skill games. }\end{array}$ & $\sqrt{ }$ & & $\begin{array}{l}\text { Task, Skills, } \\
\text { Agents }\end{array}$ \\
\hline $\begin{array}{l}\text { Hoefer et al. } \\
\text { [19] }\end{array}$ & $\begin{array}{l}\text { Network-based coalition } \\
\text { formation. }\end{array}$ & & $\sqrt{ }$ & $\begin{array}{l}\text { Coalition } \\
\text { size by } \\
\text { vertices, } \\
\text { Profit } \\
\text { (payoff) }\end{array}$ \\
\hline $\begin{array}{l}\text { Pillai and } \\
\text { Rao [20] }\end{array}$ & $\begin{array}{l}\text { Virtual machine to } \\
\text { perform resource } \\
\text { allocation. }\end{array}$ & $\sqrt{ }$ & $\sqrt{ }$ & $\begin{array}{l}\text { Task, } \\
\text { Capability, } \\
\text { Agents, } \\
\text { Payoff }\end{array}$ \\
\hline $\begin{array}{l}\text { Sless et al. } \\
\text { [5] }\end{array}$ & $\begin{array}{l}\text { Coalition structures in a } \\
\text { social network (human- } \\
\text { centric). }\end{array}$ & $\sqrt{ }$ & & $\begin{array}{l}\text { Relationship, } \\
\text { Coalition } \\
\text { size }\end{array}$ \\
\hline $\begin{array}{l}\text { Goradia and } \\
\text { Vidal [21] }\end{array}$ & $\begin{array}{l}\text { Negotiation based } \\
\text { coalition formation. }\end{array}$ & $\sqrt{ }$ & $\sqrt{ }$ & $\begin{array}{l}\text { Tasks, } \\
\text { Agents, } \\
\text { Coalition } \\
\text { size }\end{array}$ \\
\hline $\begin{array}{l}\text { Pechoucek et } \\
\text { al. [7] }\end{array}$ & $\begin{array}{l}\text { Knowledge based } \\
\text { coalition for } \\
\text { humanitarian (human- } \\
\text { centric). }\end{array}$ & $\sqrt{ }$ & & $\begin{array}{l}\text { Task, Agent } \\
\text { Type, } \\
\text { Knowledge }\end{array}$ \\
\hline $\begin{array}{l}\text { Boella et al. } \\
{[6]}\end{array}$ & $\begin{array}{l}\text { Coalition via social } \\
\text { networks (human- } \\
\text { centric). }\end{array}$ & $\sqrt{ }$ & & $\begin{array}{l}\text { Agent Type, } \\
\text { Relationship, } \\
\text { Coalition } \\
\text { size }\end{array}$ \\
\hline $\begin{array}{l}\text { Shehory and } \\
\text { Kraus [22] }\end{array}$ & $\begin{array}{l}\text { Task allocation for } \\
\text { autonomous agents. }\end{array}$ & $\sqrt{ }$ & $\sqrt{ }$ & $\begin{array}{l}\text { Task, } \\
\text { Capability, } \\
\text { Payoff }\end{array}$ \\
\hline
\end{tabular}

a. CA stands for Cooperative Agent, SA stands for Selfish Agent)

In SKCF model, the main factors are adopted. The task needs capability, skill or knowledge to define type of task set to be achieved. In SKCF, human individuals are set as agents thus each individual has set of skills or knowledge which is important in forming a coalition. To summarize, the factors adopted from the Table I are as follows:

- Task: to determine the type of task needed to be carried out.

- Knowledge/Skills/Capability: termed as 'Knowledge and Skills'.

- Size/Constraint: as the coalition constraint.

- Payoff: tied with Agent factor. The factors that influence the payoff are defined by social factors.

- Relationship: relationship among agents based.

- Agent: representing human individual.

A new factor is introduced in addition to the compiled coalition factor:

- Group: introduced to store the coalitions that have been formed and completed task successfully that can be reused for future coalition formation.

Fig. 1 depicts the coalition factors organization in SKCF. Each task has sub-coalitions that need to complete their tasks. The coalition size limits number of sub-coalitions and in each sub-coalition; there are $n$ number of agents. SKCF implies equilibrium where sub-coalitions need to be equally 
distributed based on knowledge or skills and the payoff defined for the individuals.

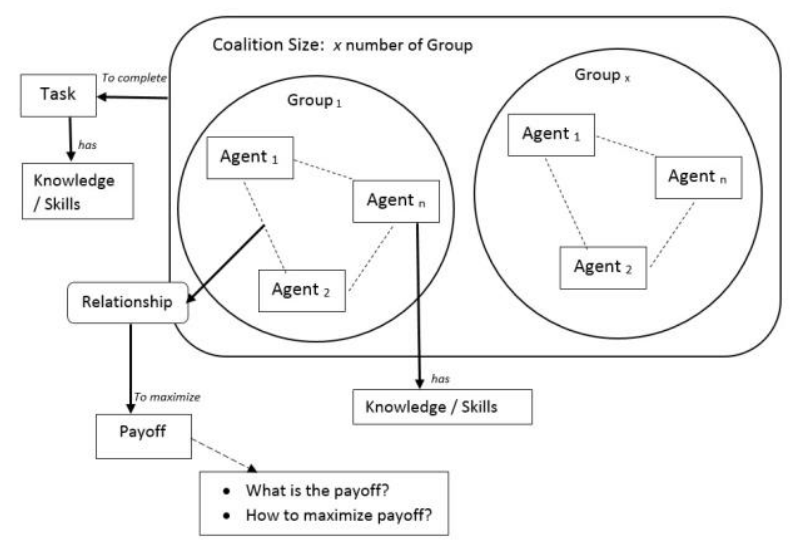

Fig. 1. Organization of the coalition factors to form a coalition.

\section{B. Identification of Social Factors}

The coalition factors are essential in forming coalition and social factors are the extension to the payoff factor by looking into factors that maximize payoff for the individuals in each group (sub-coalitions).

The payoff used in SKCF is motivated to maximize the satisfaction of people in their groups and perceive of performance to complete the task, and to be in equilibrium distribution among the sub-coalitions. The social factors are taken from literature review as presented in Table II for factors that maximize satisfaction and Table III for factors that maximize performance.

As seen in Table II and Table III, many researchers have used the Big-5 personality traits to measure the performance and satisfaction of a group. The knowledge and skills, trust and demographic background are some other factors listed.

Hence, since there is no clear-cut and definite model, some of these factors are adopted and combined to realize the SKCF knowledge base and the following factors are adopted:

- Knowledge and Skill (overlaps with coalition factor and acts as an intermediary between both factors).

- Personality (from Big-5 personality traits).

- Demographic Background.

- Trust.

TABLE II: COMPILATION OF SOCIAL FACTORS THAT MAXIMIZE SATISFACTION

\begin{tabular}{|l|l|}
\hline \multicolumn{1}{|c|}{ Reference } & \multicolumn{1}{c|}{ Factors } \\
\hline $\begin{array}{l}\text { Balasuriya and Perera } \\
\text { [23] }\end{array}$ & $\begin{array}{l}\text { Big-5: Agreeableness, Conscientiousness, } \\
\text { Extraversion, Openness }\end{array}$ \\
\hline $\begin{array}{l}\text { El-Hilali and Al- } \\
\text { Rashid [24] }\end{array}$ & Big-5: Agreeableness \\
\hline Mehrad et al. [25] & $\begin{array}{l}\text { Big-5: Agreeableness, Conscientiousness, } \\
\text { Openness }\end{array}$ \\
\hline Acuña et al. [26] & Big-5: Agreeableness, Conscientiousness \\
\hline Peeters et al. [27] & $\begin{array}{l}\text { Big-5: Agreeableness, Neurotism, } \\
\text { Conscientiousness }\end{array}$ \\
\hline Hamlyn-Harris [28] & Demographic: Gender \\
\hline Allen et al. [29] & Trust \\
\hline Keyton, [30] & Trust \\
\hline
\end{tabular}

a. Big-5 stands for Big-5 Personality Traits
TABLE III: COMPILATION OF SOCIAL FACTORS THAT MAXIMIZE

\begin{tabular}{|l|l|}
\multicolumn{1}{|c|}{ Reference } & \multicolumn{1}{c|}{ Factors } \\
\hline Prewett et al [31] & Big-5: Conscientiousness \\
\hline Amir et al. [32] & Big-5: Agreeableness, Openness \\
\hline $\begin{array}{l}\text { O'Neill and Allen } \\
\text { [33] }\end{array}$ & Big-5: Conscientiousness \\
\hline $\begin{array}{l}\text { Baninajarian and } \\
\text { Abdullah [34] }\end{array}$ & $\begin{array}{l}\text { Knowledge and skill, Experience, } \\
\text { Demographic }\end{array}$ \\
\hline Peeters et al. [35] & Big-5: Conscientiousness, Agreeableness \\
\hline Allen et al. [29] & Knowledge or Skill \\
\hline
\end{tabular}

a. Big-5 stands for Big-5 Personality Traits

\section{Combining Social and Coalition Factors}

Fig. 2 shows the compilation of social and coalition factors for SKCF.

1) Task: Coalition depends on the task thus needs to be determined, which is derived from user (in administrator level) request for a coalition. Description of a task is stored together with the type of knowledge and skill needed. Knowledge and skill factor describes the type of task to be carried out.

2) Knowledge and Skills: Knowledge and skills connects both coalition and social factors. As a coalition factor, it describes the type of tasks that needs to be performed whereas as a social factor, it is defined as sets of knowledge and skills of an individual.

3) Size/Constraints: The limitation of a coalition in terms of coalition size (for number of sub-coalitions) and constraints whether it will be a flexible coalition or strict coalition (for maximum number of people in a group), needs to be defined before coalition formation. Such constraints are to be pre-defined by the administrative user.

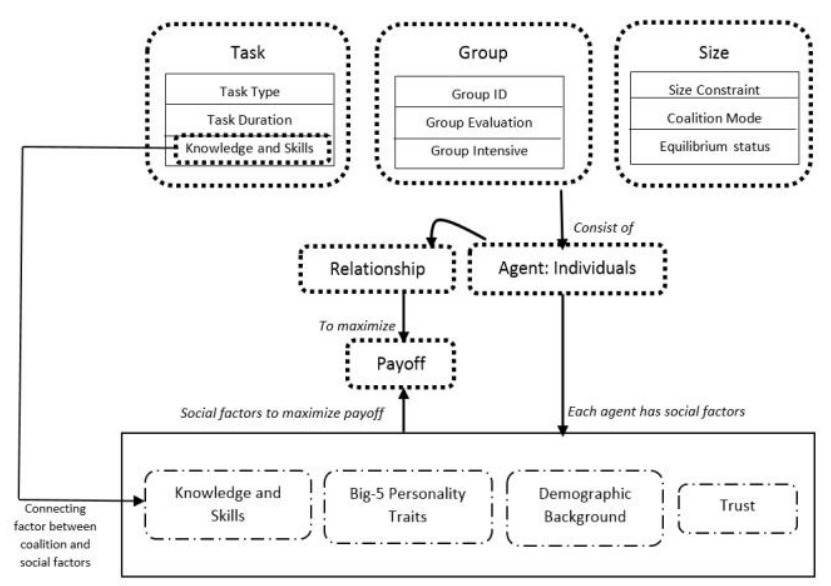

Fig. 2. Compilation of social and coalition factors for SKCF.

4) Payoff: Attained by maximizing satisfaction and performance in the formation of groups. In coalition formation mechanism, these payoff value applied as the objective function to find the optimal distribution of groups. Incentives is also included as a payoff. For example, when task has completed, the coalition administrator can give some incentives in terms of grades or marks.

5) Group: The sub-coalitions that are formed and successfully completed the task are stored as a log in the knowledge base, kept for administration knowledge or future reuse of the coalition formation. The evaluation of 
the groups is included which will be based on payoff of satisfaction and performance evaluation via user-acceptance study after tasks completed. The incentives value is also stored as a part of knowledge about groups that had been successfully formed.

6) Relationship: Acts as an intermediary that connects the group to individual. In each group, there are a number of agents and the relationship among the agents are evaluated by calculating the payoff values. The type of relationship of each other are also defined and their value of trust to each are added to define the strength of their relationship among each other.

7) Agent: Represents individuals that will be grouped into sub-coalitions where each individual in each group is represented by the social factors.

a) Knowledge and Skills (same as Factor 2): Designed to be a mandatory factor and related to the same set of knowledge and skills needed for the task to be carried out. Individuals are allowed to store and update this factor from time to time where it covers level of expertise in the particular knowledge and skills. The work experience of a person in a particular department or area is also included.

b) Personality: As shown in Table II and Table III, Big-5 traits can improve a team's performance and satisfaction. In the SKCF, the Big-5 personality traits are derived when the users sign up to the system, as they are required to answer a standard Big-5 questionnaire set. Scores from the percentile of each trait are stored in the ontology, to be used in the coalition formation mechanism.

c) Demographic background: Also known as personal characteristics such as age, gender etc. Not all tasks need this factor to decide a coalition. Hence, administrator are given the option whether the demographic constraints are needed for the coalition formation. Thus it is not mandatory but can be added whenever necessary.

d) Trust: Trust is evaluated based on rating among each other, which can be updated from time to time. This affects the weight of relationships among the individuals.

\section{ONTOLOGY REPRESENTATION FOR SOCIAL AND COALITION FACTORS}

The ontology is developed using the OWL that is based on RDF schema and employs the FOAF specifications method. The two ontology main classes for coalition are task and group. Size is set as constraint to the coalition thus the property of size is represented under the task class. The processing of a coalition will be handled by a clustering technique by mapping the FOAF knowledge base. Two main classes that represent individual are the knowledge and skill factor, and personality factor. Besides that, the classes for demographic background and trust factors are defined as well.

\section{A. Organization of the Category of Factors in Classes}

Aside from the main classes based on the factors, there are other classes that have been included to connect the classes in the form of an organization. A framework of ontology representation is built based on these classes, as depicted in Fig. 3 to show the flow of the factors in the knowledge base. The task factor is named as assignment in the ontology representation.

\section{B. Categorizing the Ontology Framework}

Table IV shows how the ontology is organized in different types of knowledge base, to ease the management of metadata. Following sections will discuss the details of the knowledge base types.

1) Skeletal base: This acts as the skeleton of the overall system where the ontology is called Social-and knowledgebased Coalition Ontology (SKCO), developed using the RDFS-OWL standard, and organized as shown in Fig. 4. The skeletal base is developed to be the standard format used by the operational knowledge base. The fragment of the SKCO is shown in Fig. 5. The 'trust' class in the SKCO is expanded based on an existing work by Golbeck and Hendler [13], where the Trust ontology is linked to the class that represents Person. The fragment of the adapted Trust ontology is shown in Fig. 6. The skeletal base can be further extended with other classes if needed.

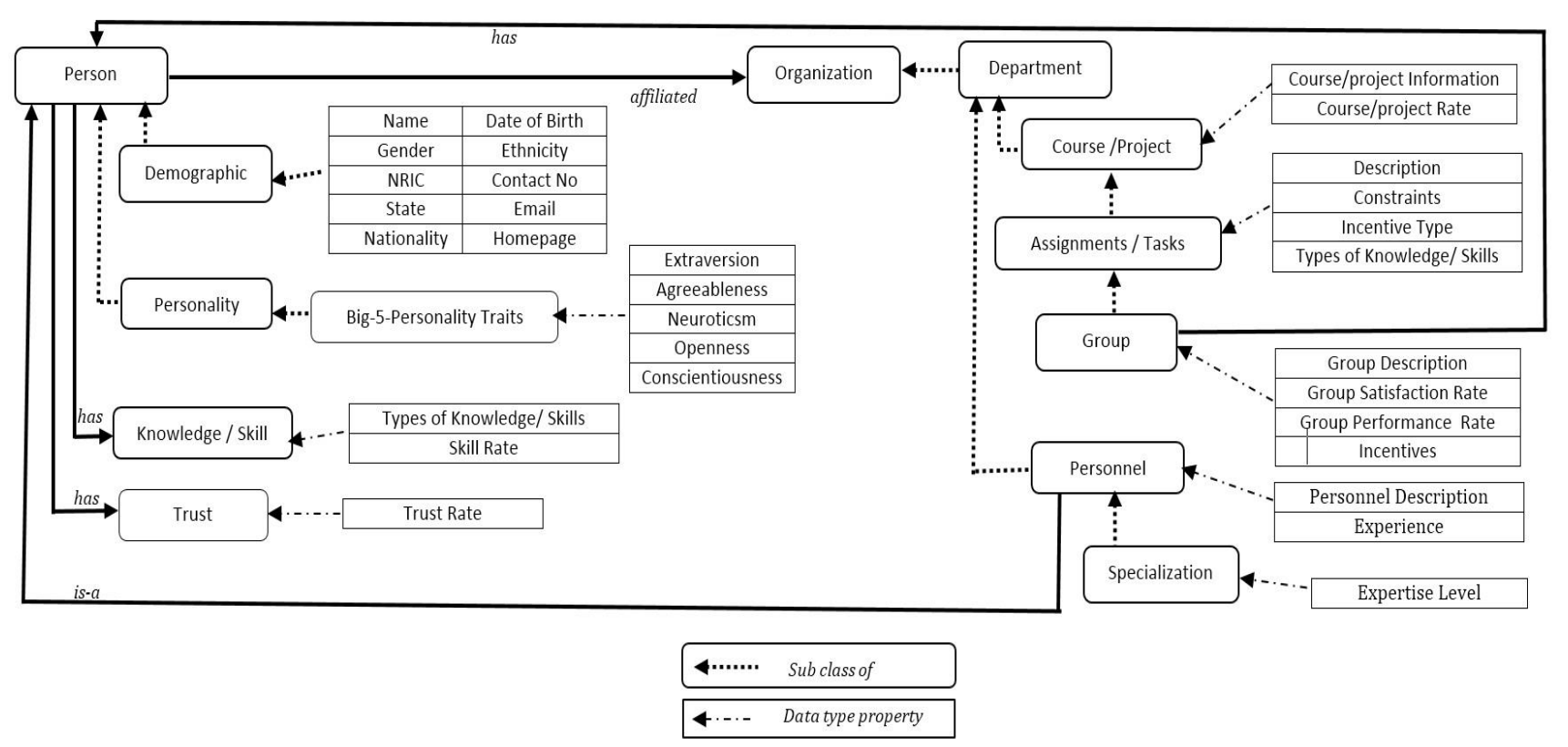

Fig. 3. The flow of the factors in the SKCF knowledge. 
2) Relationships: The relationship ontology is added in order to define the relationship among the individuals using an available ontology by Davis [37] which is a form of vocabulary to describe relationships between people. The fragment of the ontology is shown in Fig. 6. This relationship metadata define relationships, which is used particularly in the operational base.

TABLE IV: MANAGEMENT OF THE KNOWLEDGE BASE
\begin{tabular}{|l|l|ll|}
\hline $\begin{array}{l}\text { Knowledge } \\
\text { Base Type }\end{array}$ & $\begin{array}{c}\text { Standard } \\
\text { Schema }\end{array}$ & \multicolumn{1}{c|}{ Storage Steps } \\
\hline $\begin{array}{l}\text { Skeletal } \\
\text { Base }\end{array}$ & RDFS-OWL & $\begin{array}{l}\text { Predefined } \\
\text { - }\end{array}$ & Admin updates when necessary \\
\hline $\begin{array}{l}\text { Relationship } \\
\text { Base }\end{array}$ & RDF & $\bullet$ & Predefined \\
\hline $\begin{array}{l}\text { Operational } \\
\text { Base }\end{array}$ & FOAF-RDF & $\bullet \begin{array}{l}\text { User indirectly updates as they } \\
\text { use the system. }\end{array}$ \\
& $\begin{array}{l}\text { Updates evaluation after } \\
\text { coalition formation. } \\
\text { Based on users interaction. }\end{array}$ \\
\hline
\end{tabular}

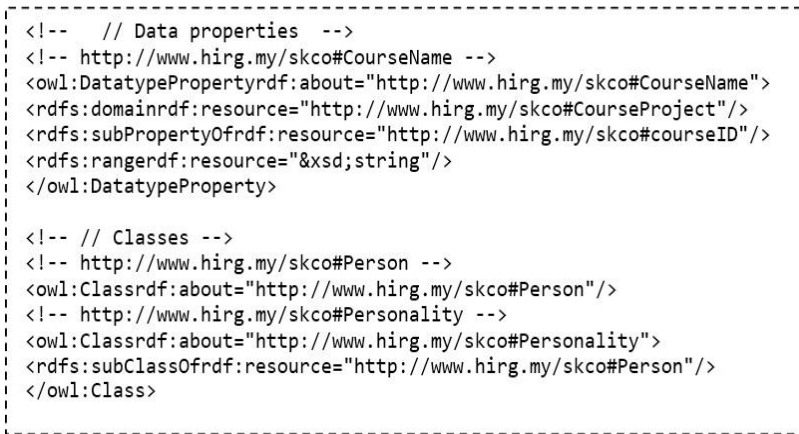

Fig. 4. Fragment of the SKCO.

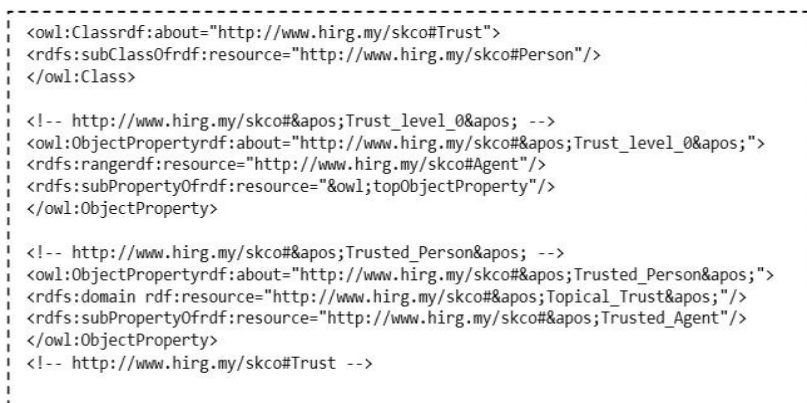

Fig. 5. Fragment of trust factors in SKCO

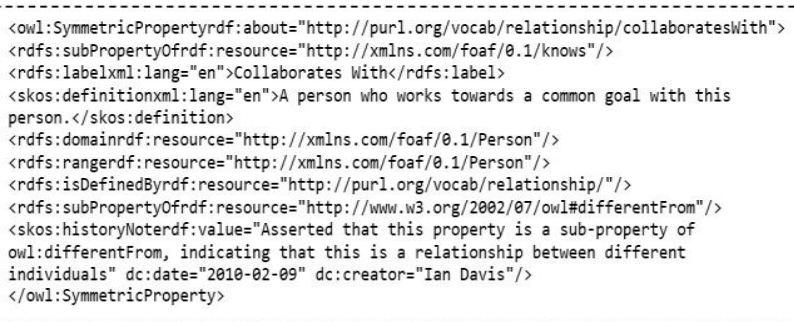

Fig. 6. Fragment of relationship ontology from Davis (2010).

3) Operational Base: New data added into knowledge base are stored in the operational knowledge base. The operational knowledge are updated from time to time to ensure the knowledge base is always "fresh" with current (new) knowledge. The knowledge in this file is retrieved to decide future coalition via clustering and optimization approach. The standard FOAF is adapted with the SKCO together with the relationship ontology. The main objects in the operational files are: 1) Person, and 2) Organization. Fig. 7 shows the fragments of operational base example for Person.

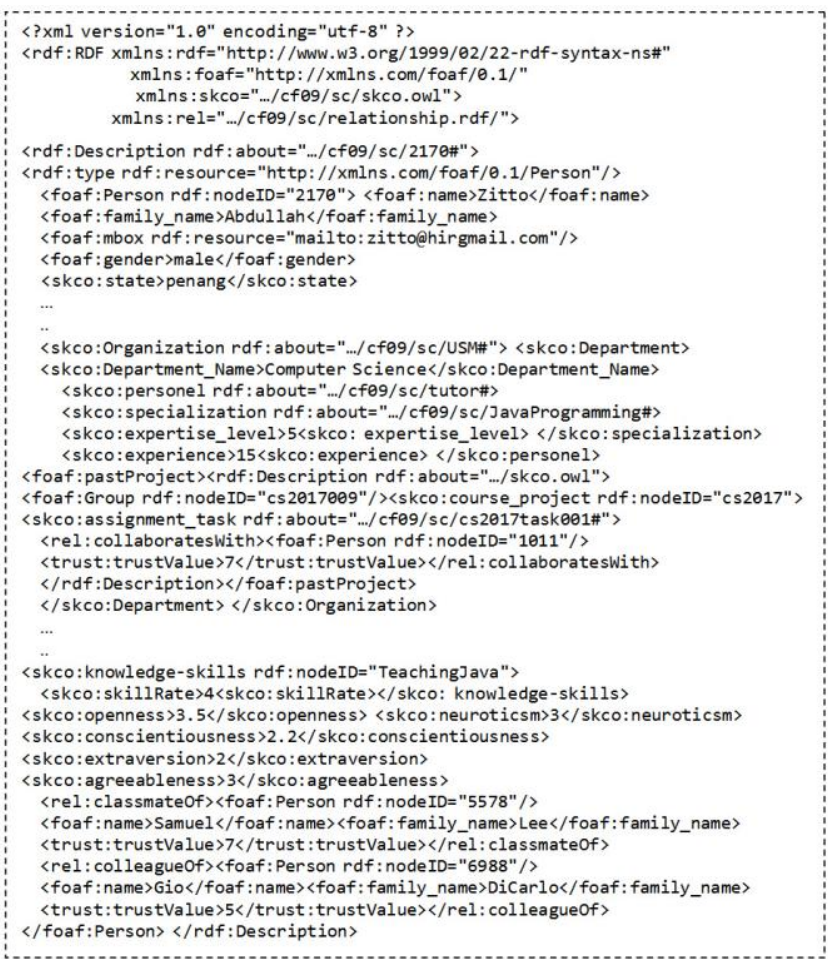

Fig. 7. Fragment of the FOAF file for person.

The fragment of the operational base example for Organization is shown in Fig. 8.

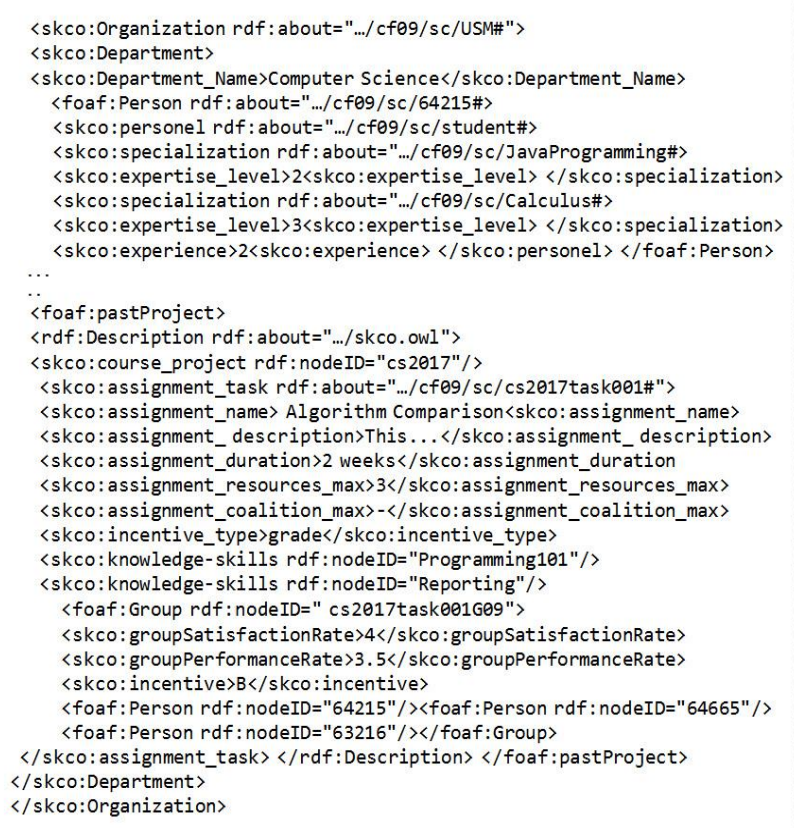

Fig. 8. Fragment of the FOAF file for organization 
The metadata from a same organization are stored in the same operational base file where knowledge of the tasks that have been carried out are represented with its respective identification. This can later be mapped to the operational base for Person category with the same identification value.

The fragment showing the metadata on group and assignment/task is also shown in Fig. 8 where groups formed under a certain task are stored together with the members in the groups.

\section{SOCIAL INTERFACE FOR THE SKCF}

In the SKCF, the component known as the social interface is created. From this component, the users are able to input information that will be stored in the FOAF knowledge base. Fig. 9 depict the process of social interface in the SKCF. When the users register to the SKCF, they need to complete their profile and one of the mandatory steps is taking the personality test based on the Big-5 personality [38].

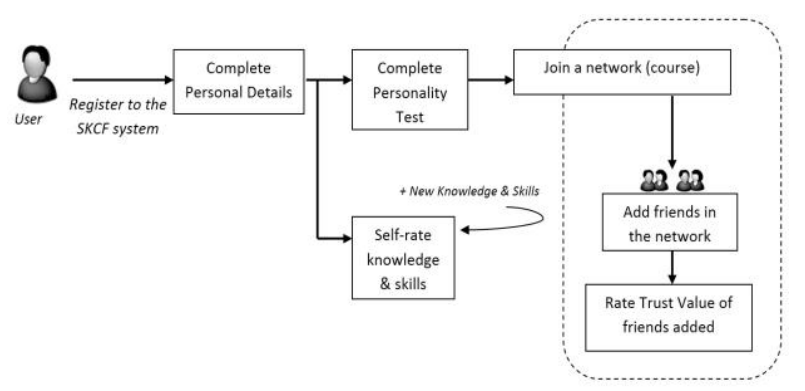

Fig. 9. The process of social interface in SKCF.

Goldberg et al. [38] presented the Big-5 questionnaire in a 50-item IPIP representation, commonly used in social sciences for personality assessment. The users are required to self-rate the knowledge and skills that are defined by administrator, and this process is triggered again when the administrator requires new sets of knowledge and skills to be rated.

Users are allowed to join a network of people under a certain project or course where they are allowed to add friends within the network and subsequently rate their trust level among each other and the values are confidential to the people who are rated. This becomes a part of knowledge that is used for coalition formation that require social factor 'Trust' to be included as the decision factor. All the input are stored in the ontology knowledge base as presented in Section IV.

\section{COALITION ENGINE FOR THE SKCF}

The coalition engine component is developed for the SKCF to enables the administrator to request for a coalition and to access the ontology. This component processes the coalition request based on the constraint set by mapping the ontology for the factors to be used in the formation.
The result is returned after running a clustering and optimization algorithm in order to find the optimal coalition formation. This will be the next direction of our research for the SKCF.

The process for the coalition engine is shown in Fig. 10. After the output of the formed coalition is produced, the administrator assigns the group to the users accordingly. The given task will be carried out by respective groups and after the task are completed, the administrator will update the knowledge base, based on the incentives given to each of the groups, i.e. grading system or monetary rewards.

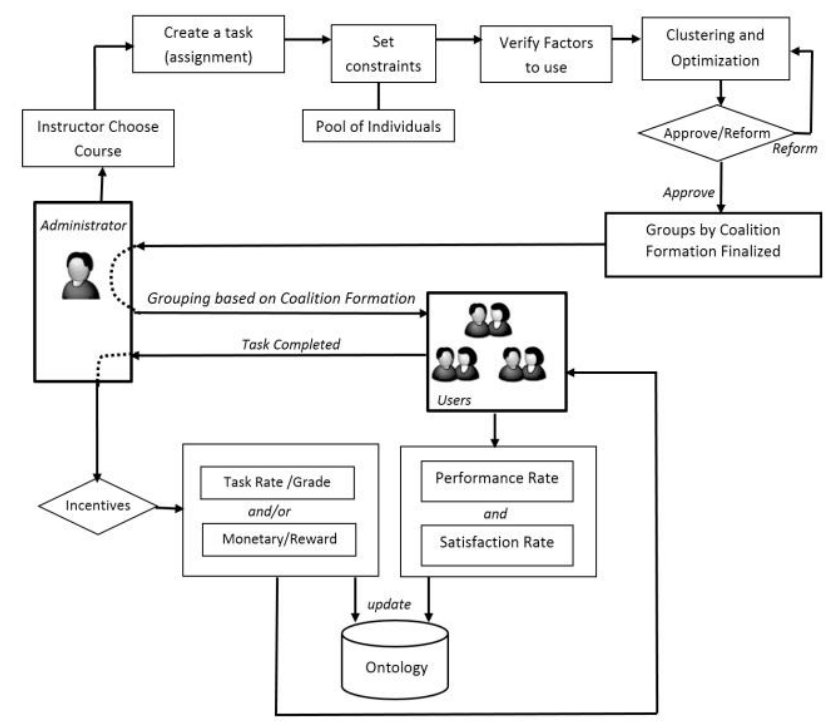

Fig. 10. The coalition engine component in SKCF.

The users are required to evaluate the coalition formation based on their satisfaction and perceive of performance in order to validate the payoff as their individual gain. This is stored in the knowledge base, and thus can be used as decision factor in future coalition formation. For example, if the rated evaluation value is lower than a set benchmark value, the coalition consisting the same members can be restricted from being formed.

\section{CONCLUSION AND FUTURE WORK}

The development of the knowledge base using the ontology representation for the social- and knowledge based coalition formation is presented. The coalition and social factors are adapted from related works on groups and coalition formation and the 'group' factor is added to enable reusability of knowledge for future coalition.

After the coalition and social factors are identified, the schema of ontology representation is produced, setting the stage for developing the knowledge base. The categories in the knowledge base are intended to help with organization and management of the knowledge. In this paper, some metadata examples from the knowledge base categories are also presented. Looking at the hierarchical form of ontology, additional classes can be extended to 
the existing ontology, for instance other external ontology related to grouping or sociology can be introduced.

The use of social network environment is the next phase of this work, where the ontology is accessed from a social networking environment to ease the users' interaction and at the same time, enriching the knowledge base.

With the ontology representation being set, the future work is to develop a suitable mechanism to access the ontology and form the coalitions. The direction of this work is focused on using a clustering and optimization method in order to achieve the cooperative agent approach of finding an optimal distribution of the coalition. Metaheuristic algortihms such as Genetic Algorithm and Particle Swarm Optimization are explored in order to address the coalition formation problem. In order to do so, the research looks into maximizing the payoff of the coalition using the coalition and social factors as presented in this paper.

\section{REFERENCES}

[1] J. V. Neumann and O. Morgenstern, Theory of Games and Economic Behaviour, Princeton: Princeton University Press, 1953.

[2] D. Ray and R. Vohra, "Coalition formation," in Handbook of Game Theory, P. Young and S. Zamir, Ed., North-Holland, 2014.

[3] E. Elkind, T. Rahwan, and N. Jennings, "Computational coalition formation," in Multiagent System, G. Weiss, Ed., The MIT Press: 2013, pp. 329-380.

[4] H. Aziz, F. Brandt, and P. Harrenstein, "Pareto optimality in coalition formation," Games and Economic Behavior, vol. 82, 2013.

[5] L. Sless, N. Hazon, S. Kraus, and M. Wooldridge, "Forming coalitions and facilitating relationships for completing tasks in social networks," in Proc. the 2014 International Conference on Autonomous Agents and Multi-Agent Systems (AAMAS'14), pp. 261-268, 2014

[6] G. Boella, L. V. Torre, and S. Villata, "Four measures for the dynamics of coalitions in social networks, " in Proc. the 20th ACM Conference on Hypertext and Hypermedia (HYPERTEXT 2009), 2009, pp. 361-362, 2009.

[7] M. Pechoucek, V. Marík, and J. Bárta, "A knowledge-based approach to coalition formation," IEEE Intelligent Systems, vol. 17, no. 3, pp. 17-25, 2002.

[8] J. H. Cho, I. R. Chen, Y. Wang, K. S. Chan, and A. Swami, Multiobjective optimization for trustworthy tactical networks: A survey and insights. [Online]. Available: http://www.dtic.mil/get-trdoc/pdf?AD =ADA588224

[9] A. Chebba, T. Bouabana-Tebibel, and S. H. Rubin, "Context in ontology for knowledge representation," in Proc. International Conference on Computer Science, Applied Mathematics and Applications (ICCSAMA 2015), 2015.

[10] D. Fensel, Ontologies: A Silver Bullet for Knowledge Management and Electronic-Commerce, Berlin: Spring-Verlag, 2003.

[11] D. Brickley, R. Guha, and B. McBride, RDF Schema 1.1. [Online]. Available: http://www.w3.org/TR/rdf-schema/

[12] P. Belsis and S. Gritzalis, "A scalable security architecture enabling coalition formation between autonomous domains," in Proc. the 5th IEEE International Symposium on Signal Processing and Information Technology (ISSPIT'05), 2005.

[13] J. Golbeck and J. Hendler, "Accuracy of metrics for inferring trust and reputation in semantic web-based social networks," Engineering Knowledge in the Age of the Semantic Web, pp. 116131, 2004.

[14] G. Albiston, T. Osman, and E. Peytchev, "Modelling trust in semantic web applications," in Proc. 16th International
Conference on Computer Modelling and Simulation (UKSimAMSS), pp. 439-444, 2014.

[15] D. Li, L. Kang, X. Cheng, D. Li, L. Ji, K. Wang, and Y. Chen, “An ontology-based knowledge representation and implement method for crop cultivation standard," Mathematical and Computer Modelling, pp. 466-473, 2013.

[16] H. Lamharhar, D. Chiadmi, and L. Benhlima, "Ontology-based knowledge representation for e-Government domain," in Proc. of the 17th International Conference on Information Integration and Web-based Applications and Services (iiWAS15), 2015.

[17] M. Sankat, R. S. Thakur, and S. Jaloree, "A framework for building ontology in education domain for knowledge representation," International Journal of Computer Science and Information Security (IJCSIS), vol .14, no. 3, pp. 399-403, 2016.

[18] Y. Liu, G. F. Zhang, Z. P. Su, F. Yue, and J. G. Jiang, "Using computational intelligence algorithms to solve the coalition structure generation problem in coalitional skill games," Journal of Computer Science and Technology, vol. 31, no. 6, pp. 1136-1150, 2016.

[19] M. Hoefer, D. Vaz, and A. L. Wagner, "Hedonic coalition formation in networks," in Proc. 25th AAAI Conference on Artificial Intelligence, pp. 929-935, 2015.

[20] P. S. Pillai and S. Rao, "Resource allocation in cloud computing using the uncertainty principle of game theory," IEEE Systems Journal, vol. 10, no. 2, pp. 637-648, 2016.

[21] H. J. Goradia and J. M. Vidal, "An equal excess negotiation algorithm for coalition formation," in Proc. the 6th International Joint Conference on Autonomous agents and multiagent systems, Honolulu, Hawaii, 2007.

[22] O. Shehory and S. Kraus, "Methods for task allocation via agent coalition formation," Artificial Intelligence vol 101, no. 1-2, pp. 165-200, 1998.

[23] B. Balasuriya and G. Perera, "The impact of personality on job satisfaction: A study of executive employees in selected private hospitals in Colombo East, Sri Lanka," Journal of Business Management, vol. 2, no. 12, pp. 7-15, 2016.

[24] N. El-Hilali and L. Al-Rashidi, "The impact of parental involvement, personality traits and organizational support on satisfaction," Procedia-Social and Behavioral Sciences, vol. 177, pp. 408-419, 2015.

[25] A. Mehrad, H. H. Hamsan, M. B. Redzuan, and H. Abdullah, "The role of personality factors on job satisfaction among academic staff at public research university," Journal of Educational, Health and Community Psychology, vol. 4, no. 1, pp. 20-28, 2015.

[26] S. T. Acuña, M. N. Gómez, J. E. Hannay, N. Juristo, and D. Pfahl, "Are team personality and climate related to satisfaction and software quality? Aggregating results from a twice replicated experiment," Information and Software Technology, vol. 57, pp. 141-156, 2015.

[27] M. A. Peeters, C. G. Rutte, H. F. Tuijl, and I. M. Reymen, "The big five personality traits and individual satisfaction with the team," Small Group Research, vol. 37, no. 2, pp. 187-211, 2006.

[28] J. Hamlyn-Harris, B. Hurst, K. V. Baggo, and A. Bayley, "Predictors of team work satisfaction," Journal of Information Technology Education, vol. 5, pp. 299-315, 2006.

[29] K. Allen, R. Bergin, and K. Pickar, "Exploring trust, group satisfaction, and performance in geographically dispersed and colocated university technology commercialization teams," in Proc. of the NCIIA 8th Annual Meeting: Education that Works, 2004.

[30] J. Keyton, Communicating in Groups: Building Relationships for Effective Decision Making, 2nd ed. New York: McGraw-Hill, 2002.

[31] M. S. Prewett, M. I. Brown, A. Goswami, and N. D. Christiansen, "Effects of team personality composition on member performance: A multi-level perspective," Journal of Group and Organization Management, pp. 1-33, 2016.

[32] F. Amir, F. Naz, S. Q. Hafeez, A. Ashfaq, and Y. H. Dogar, "Measuring the effect of five factor model of personality on team performance with moderating role of employee engagement," Journal of Psychology and Behavioral Science, vol. 2, no. 2, pp. 221-255, 2014. 
[33] T. A. O'Neill and N. J. Allen, "Personality and the prediction of team performance," European Journal of Personality, vol. 25, pp. $31-42,2011$

[34] N. Baninajarian and Z. Abdullah, "Groups in context: A model of group effectiveness," European Journal of Social Sciences, vol. 8 , no. 2, pp. 335-340, 2009.

[35] M. A. Peeters, H. Tuijl, C. G. Rutte, and I. M. Reymen, "Personality and team performance: A meta-analysis," European Journal of Personality, vol. 20, no. 5, pp. 377-396, 2006.

[36] I. Davis, (2010). RELATIONSHIP: A vocabulary for describing relationships between people. Retrieved 2017 October. [Online]. Available: http://purl.org/vocab/relationship

[37] L. R. Goldberg, "A broad-bandwidth, public domain, personality inventory measuring the lower-level facets of several five-factor models," in Personality Psychology in Europe, L. R. Goldberg, I. Mervielde, I. Deary, F. D. Fruyt, and F. Ostendorf Eds., Tilburg University Press, 1999, pp. 7-28.

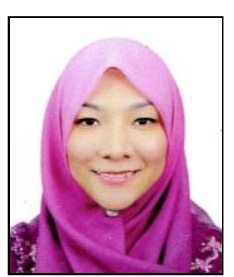

Azleena Mohd Kassim received her B.Comp.Sc (Hons) in 2004, followed by M.Sc in 2007 and Ph.D. in 2018 from Universiti Sains Malaysia. She currently works as a lecturer in School of Computer Sciences, Universiti Sains Malaysia. Her research interests are knowledge management, evolutionary computing, cooperative computing methods and artificial intelligence.

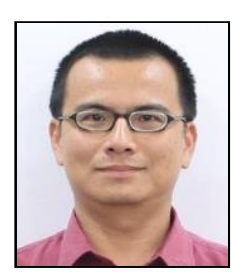

Yu-N Cheah received his B.Comp.Sc. (Hons) and $\mathrm{Ph} . \mathrm{D}$ degrees from Universiti Sains Malaysia in 1998 and 2002, respectively. He is currently an associate professor at the School of Computer Sciences, Universiti Sains Malaysia. His research interests include knowledge management, intelligent systems, health informatics, and semantic technologies.

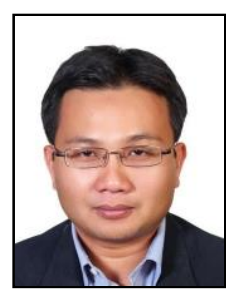

Bukhary Ikhwan Ismail received his B.Comp.Sc. (Hons) and MSc degrees from Universiti Sains Malaysia in 2005 and 2007, respectively. He currently works at the Advanced Computing Lab, Malaysian Institute of Microelectronic Systems, MIMOS Malaysia. Bukhary does research in distributed computing, cloud computing, edge computing and search infrastructure. His current work is in search infrastructure management 